\section{Case Reports in Neurology}

Case Rep Neurol 2020;12:207-211

DOI: $10.1159 / 000504128$

Published online: December 14, 2020
(C) 2020 The Author(s)

Published by S. Karger AG, Basel www.karger.com/crn

This article is licensed under the Creative Commons Attribution-NonCommercial 4.0 International License (CC BY-NC) (http://www.karger.com/Services/OpenAccessLicense). Usage and distribution for commercial purposes requires written permission.

\title{
"Cortical" Wrist Drop due to a Cerebral Peduncle Infarct
}

\author{
Narayanaswamy Venketasubramanian ${ }^{a} \quad$ Amogh Narayan Hegde $^{b}$ \\ Yeow Wai Lim

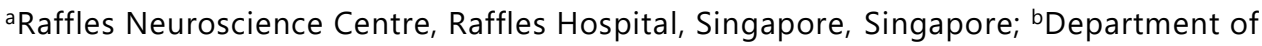 \\ Diagnostic Radiology, Raffles Hospital, Singapore, Singapore; 'Raffles Orthopaedic \\ Centre, Raffles Hospital, Singapore, Singapore
}

\section{Keywords}

Stroke $\cdot$ Infarct $\cdot$ Wrist drop $\cdot$ Cerebral peduncle

\begin{abstract}
Wrist drops are usually due to a peripheral neuropathy affecting the radial nerve. Cortical wrist drops may occur, usually due to a lesion in the contralateral hand area of the motor cortex. We report a unique case of "cortical" wrist drop due to an acute infarction of the contralateral cerebral peduncle. The patient is a 70-year-old gentleman with the vascular factors of hypertension, hyperlipidaemia, and prior cerebellar strokes, who developed sudden onset of right wrist weakness without numbness. Neurological examination showed a right wrist and finger drop. Nerve conduction study of the radial nerve was normal. MRI brain revealed an acute infarct in the medial part of the left cerebral peduncle, extending slightly to the medial thalamus; there were also old medial posterior cerebellar infarcts. Time of flight MR angiography was normal, with hypoplastic right vertebral artery. Echocardiography was normal but for a dilated right atrium. Electrocardiogram was normal, and 24-hour Holter monitoring detected infrequent atrial and ventricular ectopics. X-ray wrist showed an old ulnar styloid fracture. Nerve conduction study of the radial nerve was normal. He was switched from aspirin to clopidogrel and underwent rehabilitation. The cerebral peduncle should not be forgotten when attempting to anatomically localise the site of the lesion when evaluating a patient with a wrist drop.




\section{Case Reports in Neurology}

Case Rep Neurol 2020;12:207-211

DOI: 10.1159/000504128

(c) 2020 The Author(s). Published by S. Karger AG, Basel www.karger.com/crn

Venketasubramanian et al.: "Cortical" Wrist Drop due to a Cerebral Peduncle Infarct

\section{Introduction}

Wrist (with finger) drops are usually due to a peripheral neuropathy affecting the radial nerve, often as it runs in the radial groove of the humerus ("Saturday night palsy"). However, lesions in the contralateral cerebral motor cortex responsible for wrist movements are being increasingly recognized as the cause of a central or "cortical" wrist drop. The underlying disease may be due to contusion [1], tumour [2], or stroke [3-8]. We report a unique case of "cortical" wrist drop due to an acute infarction not of the contralateral cerebral cortex, but rather of the contralateral cerebral peduncle, and explain the anatomical basis for its occurrence.

\section{Case Report/Case Presentation}

The patient is a 70-year-old gentleman with the vascular factors of hypertension, hyperlipidaemia, and prior cerebellar strokes, as well as surgery for inguinal hernia and cataracts, chronic obstructive airway disease, old right olecranon fracture, rectal and penile bleeding, and frequent falls from giddiness. He was admitted after he developed giddiness and fell. On getting up, he noticed right wrist and finger extension weakness without numbness. Neurological examination revealed no aphasia, anopia, or neglect. Pupils were equal and reactive with bilateral intraocular lens implants. Eyes, face, palate, and tongue movements were normal, speech was slightly slurred. Limb tone, reflexes, pain sensation, and coordination were normal. Motor examination revealed a severe right wrist and finger drop power with $0 / 5$ on the MRC scale. Wrist flexion had almost full power; finger flexion and abduction was $2 / 5$ but became almost full when the wrist and fingers, respectively, were supported in extension. Shoulder abduction/adduction/flexion/extension and elbow flexion/extension had full power. MRI brain revealed an acute infarct in the medial part of the left cerebral peduncle, extending slightly to the medial thalamus (Fig. 1); there were also old medial posterior cerebellar infarcts. Time of flight MR angiography was normal, with hypoplastic right vertebral artery (Fig. 2). Echocardiography was normal but for a dilated right atrium, with no right-toleft shunt. Electrocardiogram was normal, and 24-hour Holter monitoring detected infrequent atrial and ventricular ectopics. X-ray wrist showed an old ulnar styloid fracture. Nerve conduction study of the radial nerve was normal. Full blood count and glucose were normal, and LDL-cholesterol was $51 \mathrm{mg} / \mathrm{dL}$. He was switched from aspirin to clopidogrel and underwent rehabilitation.

\section{Discussion}

A wrist drop refers to the inability to actively extend the hand at the wrist. It is due to weakness of the wrist extensors, namely extensor carpi radialis longus, extensor carpi radialis brevis, and extensor carpi ulnaris muscles, all innervated by the radial nerve or its branches. There is also concomitant weakness of finger extension due to weakness of the long finger extensors: extensor digitorum, extensor digiti minimi, abductor pollicis longus, extensor pollicis, extensor pollicis longus, and extensor indicis, all of which are supplied the posterior interosseous nerve, the main motor branch of the radial nerve in the forearm.

\section{Karger'=}




\section{Case Reports in Neurology}

Centrally, the motor area controlling hand and wrist movements lies in the lateral side of the contralateral cerebral cortex in the motor homunculus. Lesions in this "hand knob" area of the motor strip would result in an inability to centrally initiate an extension movement of the contralateral wrist and fingers, resulting in a cortical wrist drop [1-10]. Interestingly, a patient with a cortical wrist drop due to posterior borderzone infarction has been reported [11].

Uniquely, ours is the first report of a cerebral peduncle lesion causing a contralateral wrist drop. It would be expected that peduncle lesions would cause a dense contralateral hemiplegia. In a meta-analysis by Jang [12], the cortico-spinal tract was localised to the middle of the cerebral peduncle, but there was conflicting data on whether the hand and foot were represented antero-posteriorly or medio-laterally. Kwon et al. [13], using the FSL tool during diffusion tensor imaging in 43 healthy volunteers, demonstrated by probabilistic location that the descending motor fibres pass through distinct areas of the peduncle, with somatotopy of the hand in the cortical spinal tract at the mid-portion of the cerebral peduncle, while the leg somatotopy lay just lateral to the hand area. The mid-peduncle location of the hand fibres demonstrated by Kwon et al. [13] corresponds exactly with the lesion seen on the MRI of our patient, who suffered his acute stroke leading to his sudden "cortical" wrist drop.

For the clinician, differentiating cerebral from peripheral cases of the wrist drop at the bedside may be a challenge. Brigo et al. [14] showed that by asking the patient with a wrist drop to hold the hand out and to clench the fist firmly, in a peripheral wrist drop, this causes further wrist drop as there is no reflex counterbalance of the forearm flexors by the wrist extensors. In a central wrist drop, clenching the fist leads to slight extension at the wrist as there is preserved synkinetic contraction of the forearm extensors with the forearm flexors.

\section{Conclusion}

While more likely peripheral, a wrist drop may be due to a central, "cortical," cause. While the lesion usually lies in the hand area of the contralateral cerebral cortex, a lesion in the cerebral peduncle may cause a similar neurological deficit. Neuroimaging is extremely helpful in localizing the site of the lesion leading to the "cortical" wrist drop. The cerebral peduncle should not be forgotten when attempting to anatomically localise the site of the lesion when evaluating a patient with a wrist drop.

\section{Statement of Ethics}

This research complies with the guidelines for human studies and was conducted ethically in accordance with the World Medical Association Declaration of Helsinki. The subject has given his informed consent to publish his case (including publication of images).

\section{Conflict of Interest Statement}

The authors have no conflicts of interest to declare.

\section{Karger'}




\section{Case Reports in Neurology}

\section{Funding Sources}

No funding was received.

\section{Author Contributions}

Narayanaswamy Venketasubramanian: conceived the idea, wrote the paper. Amogh Narayan Hegde: discussed the idea, provided and interpreted the neuroimages, critically reviewed the paper. Yeow Wai Lim: discussed the idea, critically reviewed the paper.

\section{References}

1 Bhatoe HS. Wrist drop and foot drop in cerebral cortical lesions. Med J Armed Forces India. 1998 Apr;54(2):167-9.

2 Folyovich A, Varga V, Várallyay G, Kozák L, Bakos M, Scheidl E, et al. A case report of isolated distal upper extremity weakness due to cerebral metastasis involving the hand knob area. BMC Cancer. 2018 Oct;18(1):947.

3 de Lima FD, Luvizutto GJ, Schelp AO, Braga GP, Bazan R. Stroke Chameleons Manifesting as Distinct Radial Neuropathies: Expertise Can Hasten the Diagnosis. Case Rep Neurol. 2017 Dec;9(3):277-83.

4 Goel K, Singh SK, Agarwal H, Mukherji JD, Kumar M. Isolated Wrist Drop Presenting as Acute Stroke: Rare Case Report with Review of Literature. J Neurosci Rural Pract. 2018 Oct-Dec;9(4):647-9.

5 Wang Y, Dong Q, Li SJ, Hu WL. New clinical characteristics and risk factors of hand knob infarction. Neurol Sci. 2018 May;39(5):857-62.

6 Kew GS, Sharma VK, Ong JJ. Isolated hand weakness. Eur J Intern Med. 2017 May;40:e5-6.

7 Tahir H, Daruwalla V, Meisel J, Kodsi SE. Pseudoradial Nerve Palsy Caused by Acute Ischemic Stroke. J Investig Med High Impact Case Rep. 2016 Jul;4(3):2324709616658310.

8 Pedroso JL, Knobel M, Massaud RM, Knobel E. Acute ischemic stroke resembling Saturday night palsy. Arq Neuropsiquiatr. 2014 May;72(5):391.

9 Dafotakis M, Schiefer J, Wiesmann M, Mühlenbruch G. [Bilateral wrist drop - central or peripheral lesion?]. Fortschr Neurol Psychiatr. 2011 May;79(5):304-6.

10 Takamiya K, Takahashi K, Kaminogo M, Baba H, Mori K. ["Drop hand” resulting from cerebral infarction case report]. Rinsho Shinkeigaku. 1989 Jun;29(6):778-80.

11 Hassan KM. Fractional arm weakness as presentation of stroke due to posterior borderzone infarct: A report of two cases. Ann Indian Acad Neurol. 2010 Oct;13(4):302-4.

12 Jang SH. Somatotopic arrangement and location of the corticospinal tract in the brainstem of the human brain. Yonsei Med J. 2011 Jul;52(4):553-7.

13 Kwon HG, Hong JH, Jang SH. Anatomic location and somatotopic arrangement of the corticospinal tract at the cerebral peduncle in the human brain. AJNR Am J Neuroradiol. 2011 Dec;32(11):2116-9.

14 Brigo F, Ragnedda G, Canu P, Nardone R. Synkinetic wrist extension in distinguishing cortical hand from radial nerve palsy. Pract Neurol. 2018 Dec;18(6):520-1. 
Case Reports in Neurology
Case Rep Neurol 2020;12:207-211

DOI: $10.1159 / 000504128$

(c) 2020 The Author(s). Published by S. Karger AG, Basel www.karger.com/crn

Venketasubramanian et al.: "Cortical" Wrist Drop due to a Cerebral Peduncle Infarct

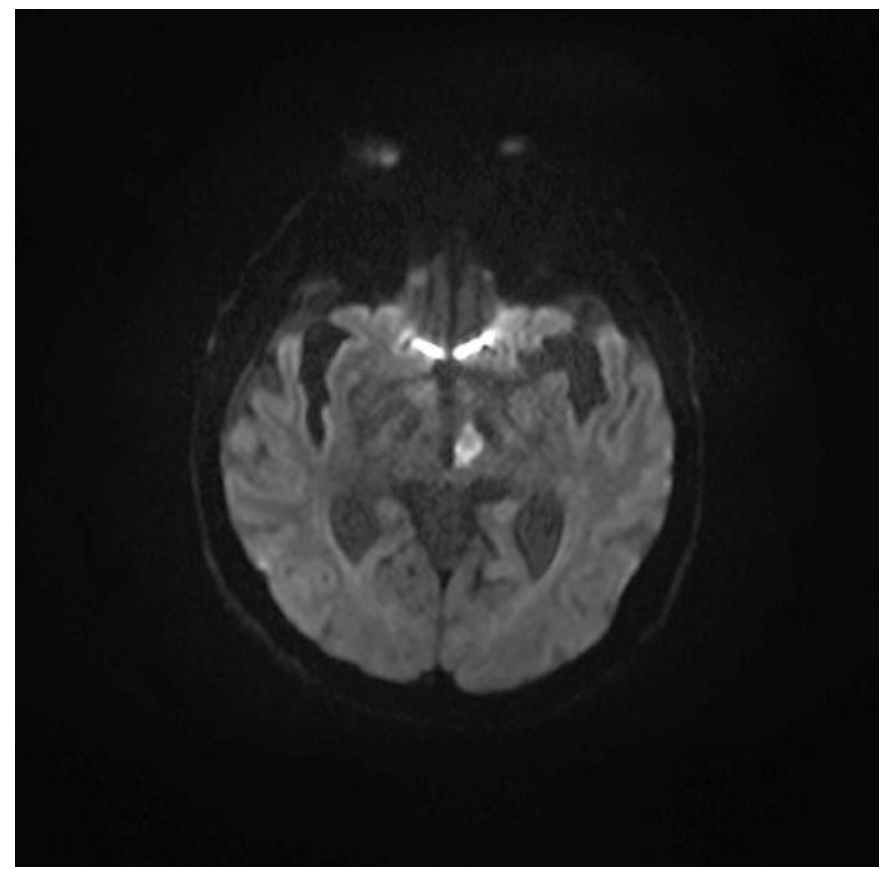

Fig. 1. MRI DWI brain showing acute ischaemic stroke in the medial left cerebral peduncle.

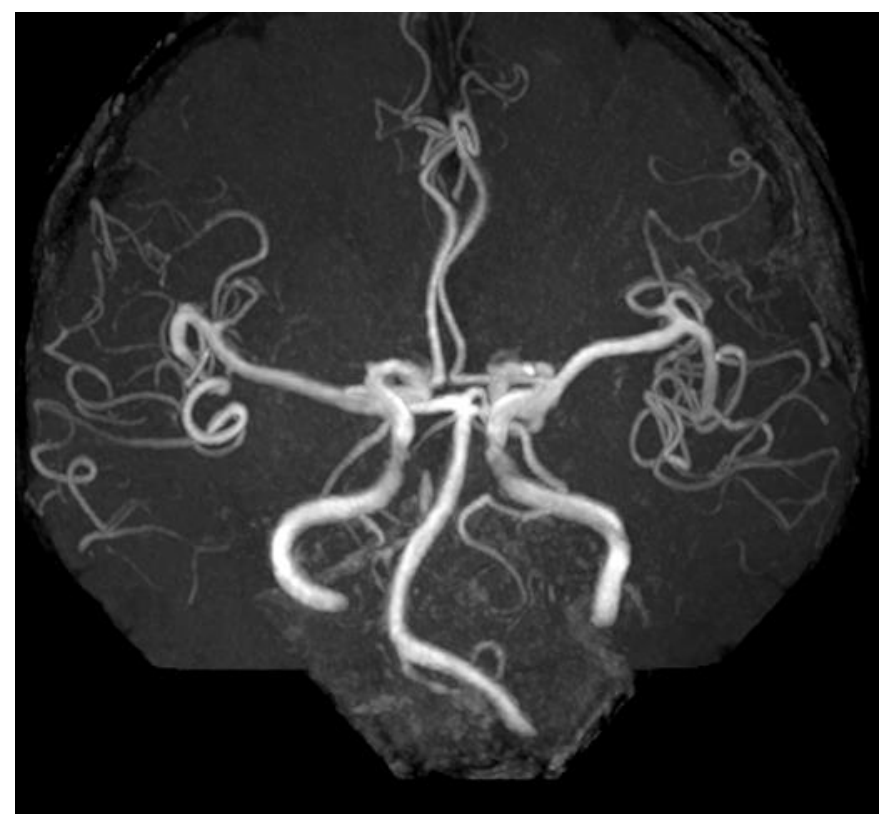

Fig. 2. Time of flight MR angiogram showing no significant stenosis of the intracranial arteries.

\section{Karger'}

